\title{
A INSTRUÇÃO PÚBLICA NA FRANÇA REVOLUCIONÁRIA: CONSIDERAÇÕES A PARTIR DO ESSAIS SUR L'ENSEIGNEMENT EN GENERAL ET SUR CELUI DES MATHÉMATIQUES EN PARTICULIER, DE SYLVESTRE-FRANÇOIS LACROIX ${ }^{1}$
}

\author{
Antonio Vicente Marafioti Garnica \\ Universidade Estadual Paulista, Brasil. \\ Maria Laura Magalhães Gomes \\ Universidade Federal de Minas Gerais, Brasil. \\ Mirian Maria Andrade \\ Universidade Federal de Uberlândia, Brasil.
}

\begin{abstract}
Resumo
O artigo aborda o livro Essais sur l'enseignement en général, et sur celui des mathématiques en particulier, de Sylvestre-François Lacroix, publicado originalmente na França em 1805, enfatizando sua primeira parte, na qual o autor discute a instrução pública e, particularmente, as escolas centrais da França revolucionária.

Palavras-chave: Sylvestre-François Lacroix (1765-1843), instrução pública, Essais sur l'enseignement en général, et sur celui des mathématiques en particulier, iluminismo, França.
\end{abstract}

\footnotetext{
${ }^{1}$ A extensão, o detalhamento e a natureza do Essais sur l'enseignement en général, et sur celui des mathématiques en particulier, de Lacroix, obra central deste estudo, impedem que sua análise integral possa ser divulgada num único artigo. Assim, os autores optaram por elaborar dois textos, publicados em diferentes periódicos, cada um deles relativo a uma das duas partes do livro. Essa estratégia implica haver algumas interseções entre esses artigos, o que aos autores pareceu inevitável com vistas a manter a coerência da abordagem e permitir a leitura de cada um deles sem ter, necessariamente, o outro como pressuposto.
} 


\section{THE PUBLIC INSTRUCTION IN REVOLUTIONARY FRANCE: SOME REMARKS ACCORDING TO LACROIX'S ESSAIS SUR L'ENSEIGNEMENT EN GENERAL ET SUR CELUI DES MATHÉMATIQUES EN PARTICULIER}

Abstract

The article discusses the book Essais sur l'enseignement en général, et sur celui des mathématiques en particulier, by Sylvestre-François Lacroix, originally published in France in 1805. The first part of the book, in which the author discusses public education, and particularly the central schools of revolutionary France, is emphasized.

Key-words: Sylvestre-François Lacroix (1765-1843), public instruction, Essais sur l'enseignement en général, et sur celui des mathématiques en particulier, enlightenment, France.

\section{INSTRUCCIÓN PÚBLICA EN FRANCIA REVOLUCIONARIA: CONSIDERACIONES A LA VISTA DEL LIBRO ESSAIS SUR L'ENSEIGNEMENT EN GENERAL ET SUR CELUI DES MATHÉMATIQUES EN PARTICULIER, DE SYLVESTRE-FRANÇOIS LACROIX}

\section{Resumen}

El artículo aborda el libro Essais sur l'enseignement en général, et sur celui des mathématiques en particulier de Sylvestre-François Lacroix, publicado originalmente en Francia, en 1805, haciendo hincapié en su primera parte, en la que el autor habla de la instrucción pública y en particular de las escuelas centrales en Francia en el período revolucionario.

Palabras-clave: Sylvestre-François Lacroix (1765-1843), instrucción pública, Essais sur l'enseignement en général, et sur celui des mathématiques en particulier, ilustración, Francia.

\section{L'INSTRUCTION PUBLIQUE EN FRANCE REVOLUTIONNAIRE: CONSIDÉRATIONS EN VUE DU LIVRE ESSAIS SUR L'ENSEIGNEMENT EN GENERAL ET SUR CELUI DES MATHÉMATIQUES EN PARTICULIER, DE SYLVESTRE-FRANÇOIS LACROIX}

Résume

L'article présente le livre Essais sur l'enseignement en général, et sur celui des mathématiques en particulier de Sylvestre-François Lacroix, à l'origine publié en France en 1805, mettant l'accent sur sa première partie, dans lequel l'auteur traite de l'instruction publique, et en particulier des écoles centrales crées pendant la Revolution Française pour remplacer des colléges et des facultés des arts des anciennes universités.

Mots-clé: Sylvestre-François Lacroix (1765-1843), instruction publique, Essais sur l'enseignement en général, et sur celui des mathématiques en particulier, lumières, France. 


\section{Um autor e as intenções historiográficas de uma obra}

á em 1782, aos 17 anos, Sylvestre-François Lacroix estava envolvido com a docência. No decorrer de sua carreira, foi professor da École des Gardes de La Marine em Rochefort, da École Royale d'Artillerie de Besançon, do Lycée ${ }^{2}$ de Paris, da École Royale Militaire, da École Centrale des Quatre-Nations, da École Polytéchnique, primeiro reitor da Faculté des Sciences de Paris, e daquele que, em 1870, depois de assumir várias denominações, passou a ser conhecido como o Collège de France. Atuou como avaliador de estudantes de Escolas de Artilharia e foi examinador permanente da École Polytéchnique.

As figuras científicas importantes mais presentes e influentes em sua carreira foram Gaspard Monge (1746-1818) e o marquês de Condorcet (1743-1794). Nomeado chef de bureau da Comissão de Instrução Pública, Lacroix desempenhou papel relevante na reforma do sistema educacional francês que implantou a Escola Normal e as Escolas Centrais. Para as Escolas Centrais, especialmente para a École Centrale des QuatreNations, Lacroix elaborou um conjunto de livros didáticos, que passou a se chamar Cours de Mathématiques, publicado entre 1797 e 1802.

No Brasil, os livros de Lacroix, amplamente traduzidos, circularam desde o início do século 19. Especialmente visando o ensino na Real Academia Militar, criada por D. João $\mathrm{VI}$, nos três primeiros anos da presença da imprensa entre nós, publicaram-se cinco traduções das obras de aritmética, álgebra, geometria e cálculo diferencial do autor. No decorrer do século 19, houve reedições desses livros e mesmo novas traduções, o que evidencia a importância da obra didática de Lacroix para a educação matemática brasileira (Schubring, 2003).

A fase mais notadamente didática da produção do autor francês encerra-se com a divulgação, em 1805, de um título voltado não aos estudantes secundaristas, mas aos professores e a um público especializado ou interessado nas questões relativas ao ensino: o Essais sur l'enseignement en général, et sur celui des mathématiques en particulier, uma coletânea de reflexões que o próprio Lacroix assume serem de caráter historiográfico sobre o ensino na França, seguida de uma descrição analítica de sua obra didática, os livros do Cours. É a primeira parte desta obra, a apresentação e a análise do modelo francês de instrução pública e, mais particularmente, das instituições criadas para o ensino secundário, as Écoles Centrales implantadas pela Revolução, que este artigo pretende considerar.

O Essais compõe-se de três partes: uma introdução, com o título Da cultura matemática durante o século 18 e da sua influência sobre o desenvolvimento do espírito humano nesse período); uma primeira parte, em que Lacroix discute a situação do ensino, em geral, no século 18, e uma segunda parte, reservada ao ensino de Matemática e a uma análise do Curso Elementar de Matemática, de sua autoria.

\footnotetext{
${ }^{2}$ Esse Lycée não deve ser confundido com os Liceus, escolas de ensino secundário implantadas na França já no período napoleônico. Segundo Domingues (2007, p. 10), o Lycée no qual Lacroix atuou entre 1786 e 1787 era uma instituição privada à qual membros da sociedade refinada de Paris recorriam para buscar cultura geral com professores renomados. Condorcet, que interferiu para a contratação de Lacroix no Lycée, era responsável pela cadeira de Matemática.
} 
Numa breve nota introdutória, intitulada Objetivo (da obra), Lacroix declara suas intenções. Redigindo na primeira pessoa do singular, o autor revela os motivos que o levaram a escrever o ensaio e relata, brevemente, sua posição e seu cenário: presentifica-se como pessoa pública, envolvida não só como professor com "uma longa experiência de ensino, adquirida em escolas muito diferentes, por métodos muito variados e sob a influência de regimes administrativos opostos", mas também como administrador, dado que foi "chamado a cooperar com o restabelecimento da instrução pública" (Lacroix, 1838, p. 3), num cenário de alterações: no "momento em que a instrução pública acaba de receber uma nova organização na qual uma certa ordem das coisas, obstruída por entraves de toda espécie, foi extinta e não pode ser julgada à luz da razão" (Lacroix, 1838, p. 1-2).

Lacroix explicita a meta específica da obra com as palavras "fixar, ao menos para a história, o verdadeiro caráter dessas instituições [...] criadas após a tormenta revolucionária" (p. 3). O autor completa essa declaração frisando o interesse de uma investigação para descobrir se as instituições educacionais "foram apenas o resultado do exagero que causou tanto mal ou se, provocadas pelo progresso das Luzes e de acordo com a opinião dos maiores homens do último século, foram propícias para a aceleração do desenvolvimento do espírito humano" (Lacroix, 1838, p. 2).

O teor historiográfico dessa obra de Lacroix torna-se, portanto, explícito já no início do texto, quando o autor enfatiza sua experiência, sua posição de espectador e ativo participante nas instâncias executivas relativas à instrução pública do período revolucionário e defende uma isenção política que lhe permitiu transitar por entre grupos, espaços e tempos cujos ideários nem sempre se mostraram coesos e convergentes.

Ter sido indicado durante o Grande Terror, também conhecido como Terror Jacobino, que dura de 1793 a 1794, para cargos de prestígio, como as posições de examinador da Escola de Artilharia em Charlons-sur Marne e de chefe de gabinete da Comissão de Instrução Pública, não significa que Lacroix tenha tido posições políticas extremadas nem mesmo que fosse jacobino. Na verdade, segundo Domingues (2007), Lacroix era moderado, com posições claramente progressistas, bem ao gosto do Iluminismo, ainda que essa têmpera não possa explicar de modo cabal a permanência do prestígio do autor. Assinalemos, logo de partida, que a defesa apaixonada dos ideais das Luzes e do modelo de instrução revolucionário é um dos principais temas do Essais, obra que teve quatro edições produzidas entre 1805 e 1838 e atravessou, assim, um momento revolucionário, o período napoleônico e alcançou a Restauração, com o retorno da Monarquia.

Destarte, o Essais não é um texto qualquer de um autor qualquer: é um depoimento, um escrito testemunhal do qual um autor específico, nomeado claramente e participante ativo nas tramas que ajudaram a constituir um sistema nacional de instrução para a França do final do século 18 pode dar conta. É, então, adequado interpretar o texto introdutório ao Essais como um pacto autobiográfico (Lejeune, 2008).

A obra está sintonizada, com efeito, na perspectiva de um contrato especial entre autor e leitor, manifestada não somente na identidade de nome entre autor, narrador e

\footnotetext{
${ }^{3}$ Em todo o artigo, as citações de trechos da obra de Lacroix foram extraídas da tradução, até o momento inédita para o português, realizada por Karina Rodrigues, com prefácio, revisão e notas de Antonio Vicente Marafioti Garnica e Maria Laura Magalhães Gomes.
} 
personagem, mas também no compromisso que Lacroix faz questão de estabelecer junto ao leitor de forma que nenhuma dúvida paire sobre sua legitimidade como testemunha. Estamos, desse modo, antes de tudo, diante de um texto autorreferencial, pactuado contratualmente com o leitor já na exposição dos Objetivos da obra. Note-se ainda que, além da identidade assumida na enunciação, que caracteriza o pacto autobiográfico, Lacroix explicita que nada tem a esconder, nada que o comprometa e que o possa impedir de dizer toda a verdade ou, pelo menos o que ele entende por toda a verdade, o que conduz a um trabalho de leitura sustentado pela ideia da veracidade do texto.

As datas de publicação da edição original e das edições subsequentes poderiam indicar o Essais como uma obra do século 19. Bastar-se à cronologia, desconsiderando os aspectos internos do objeto investigado, porém, não parece ser indicado. O livro foi publicado em 1805, com reedições em 1816, 1828 e 1838, mas mesmo uma leitura superficial de quaisquer dessas edições ${ }^{4}$ mostrará que são muito mais presentes no texto as marcas do século 18 que as do século 19, no qual efetivamente a obra circulou. Defenderemos, portanto, que os Ensaios sobre o ensino em geral, e o de Matemática em particular exploram o século 18, promovem o século 18, trazem entranhadas as cicatrizes do século 18.

\section{Uma obra com a autenticação do século das Luzes circula no século 19}

As marcas do século 19 são muitas e nítidas: estão na tração motora, no processo automatizado da produção em série e no fascínio que eles exercem desde que se insinuou na Inglaterra a Revolução Industrial; na procura febril pela fotografia, registro de uma singularidade distinta daquela dos retratos aristocráticos e morosos que a invenção de Daguerre popularizara; na comodidade do telégrafo; nas invenções que atualizam e tornam mais ágil o sistema de impressão gráfica e potencializam a propaganda; no surgimento de um novo comércio, competitivo, em grande escala, cuja distribuição é acelerada pelos grandes magazines; no cinema, que presentifica em movimento o já passado; na eletricidade; no automóvel; na indústria química. Num mesmo século, duas modernidades, duas revoluções industriais: a primeira, simbolizada pelas maquinarias; a segunda, incorporando à simbologia dos motores um aparato técnico poderoso de representações e comunicações que dinamiza ainda mais as relações sociais, políticas e econômicas (Ortiz, 2000).

É possível compreender o século 19 a partir de Paris, a então capital do mundo (Benjamin, 1991), em que as galerias, passagens cujas arcadas, proteção do comércio da elite e espaço diferenciado de socialização, pouco a pouco passam a sufocar, tornandose clausuras, e exigem a construção de espaços cada vez mais amplos: não mais o mero mercado de novidades, mas o dos grandes magazines, espaços de nova arquitetura que potencializa o volume dos negócios que, agora buscado feericamente, precisa ser acessado pelas grandes avenidas projetadas por Haussmann. Não apenas arcadas, mas arcadas gigantescas, cuja construção o ferro e o vidro, não as pedras, possibilitam.

Se até metade do século 19 Paris era ainda uma "rede densa de pequenas células autônomas" (Ortiz, 2000, p. 17), sem relação umas com as outras, que as passagens

\footnotetext{
${ }^{4} \mathrm{O}$ cotejamento entre as quatro edições do Essais nos permite afirmar que o corpus do texto permanece relativamente inalterado. A exceção são as notas, cuja quantidade se altera radicalmente, num movimento crescente, em cada uma das edições.
} 
apenas ligavam sem romper sua incomunicabilidade, o projeto de Haussmann racionaliza o espaço urbano promovendo o fluxo dos veículos, em quantidade cada vez mais crescente, e a mobilidade das pessoas que, por sua vez, exige um sistema de transporte público para o trânsito no rendilhado de pontes, praças e boulevards que dão ao tecido urbano de Paris uma trama nervosa.

Há, no século 19, uma França do Norte, industrializada, moderna, urbana, e uma França do Sul, agrícola, tradicional, atrasada (Ortiz, 2000), do mesmo modo como há a flânerie nas passagens, os pequenos mercados de luxo que se mantêm pelos nomes de comerciantes e famílias que os dirigem, e o indivíduo; e a urgência, a pressa, o consumo popularizado, os grandes magazines, a multidão. $O$ processo de negação de um Antigo Regime torna-se, de fato, o movimento de popularização das comodidades do Antigo Regime, que agora se estendem e alcançam diversas classes sociais. Ainda que Victor Hugo nos permita acessar a Paris miserável das multidões e Baudelaire nos ajude a compreender a viagem estática do flâneur que habita o provisório, é de Eça de Queirós, em $A$ cidade e as serras, uma das mais eloquentes configurações dessa Paris plural, desenraizada, dinâmica, moderna, cujas garras se insinuam por todos os cantos e na qual Jacinto de Tormes, o protagonista, não concebe a vida sem os confortos e as modernidades da civilização, resultantes da igualdade que sintetiza sua filosofia de vida: "suma ciência $\mathrm{x}$ suma potência = suma felicidade".

O século 18, por sua vez, é marcado por ventos revolucionários na política, na economia, na demografia, na cultura de outra natureza, ou de natureza complementar, já que as modernidades do século 19, mesmo que plasmadas em bases materiais distintas entre si e obviamente distintas daquelas do século anterior, têm como fator preponderante as relações produtivas, um sistema político que sustenta essas relações produtivas, uma coletividade que mantém e subverte um sistema e um complexo ideário que atravessa esses mundos interligados e se deixa representar fortemente por uma outra revolução, a Francesa, "um dos raros acontecimentos que redefiniram a condição humana e redirecionaram o curso da história" (Darnton, 1990, p. 14).

Seguindo paralelo às tramas revolucionárias, há todo um sistema de ideias, também ele revolucionário, pouco a pouco gestado na Europa, que cativa até mesmo a nobreza e cujo auge se dá com os philosophes franceses: o lluminismo. Não é possível, entretanto, afirmar a implicação direta, num único sentido, entre as Luzes e a Revolução. Se há a defesa de que tal poderoso conjunto de ideias, que questiona fazeres, poderes e saberes alimentou os ânimos revolucionários, há também a possibilidade de ter sido tal sistema potencializado pela própria Revolução. Tal discussão é ainda pertinente, como o são todas as versões históricas quando concebemos a historiografia como um campo de conflitos discursivos.

A vinculação entre historiografia e positivismo, no primeiro centenário da Revolução, promoveu Danton como herói e símbolo das conquistas revolucionárias: seu caráter inspirado, seu espírito reto, seu compromisso com a pátria o haviam levado, por ser necessário, a promover o Terror e, quando tornado possível, a tentar revertê-lo. Já nas comemorações do segundo centenário, quando um novo ideário regia a prática da historiografia e predominava na França uma política centrista que professava abertamente sua intenção de inscrever o país como protagonista na criação da União Européia, Danton 
e Robespierre deveriam ser deixados de lado: era preciso forjar a ideia de uma França em paz consigo mesma:

um povo a salvo de disputas, desfrutando tranquilamente dos direitos humanos que constituem o verdadeiro patrimônio revolucionário, confiante na maturidade das instituições francesas e em sua aptidão para encarar os desafios e as oportunidades de uma nova ordem européia [...]. Nenhum indício de subsequente radicalização, nenhum eco de conflito social, nenhuma sombra do Terror poderia macular essa temporada de comemorações. [...] O herói de 1989 foi Condorcet: sábio, filósofo, reformista, revolucionário, 'moderado', vítima da Revolução [que] não conseguiu se sobrepor nem se fazer vigorar. (Chartier, 2009, p. 14)

Assim como os registros sobre a Revolução, portanto, estão sujeitos à sintonia fina ditada pelos momentos e contextos, também a relação entre Revolução e lluminismo é discutida em meio a conflitos. Um dos principais focos de Chartier, em Origens culturais da revolução francesa, para tratar dessa questão, é a variedade de elementos que constituem o tecido cultural francês do período que antecede o final do século 18, como o processo de descristianização das vilas e cidades, a produção e circulação da produção literária, o acelerado e crescente questionamento sobre a origem e a pertinência do poder do rei e da aristocracia, entre outros, concluindo que, se para alguns autores, é possível defender que os livros filosóficos, suporte por excelência do ideário das Luzes, produziram uma erosão ideológica que pode ter tornado inevitável a ruptura revolucionária, em certo sentido pode-se também afirmar que 'foi a Revolução que 'fez' os livros, já que foi a Revolução que deu um significado premonitório e programático a certas obras, atribuindo esse significado às suas origens após o fato estabelecido" (Chartier, 2009, p. 143).

De certo, porém, tem-se que o advento da Revolução subverte o postulado prático corrente de que a vida deve manter-se nos moldes do prosaico comum, como diria Darnton, já que, hoje, a

maioria de nós vive num mundo que consideramos não o melhor, mas o único possível. A Revolução Francesa desapareceu aos poucos num passado quase imperceptível. Seu brilho foi obscurecido por uma distância de duzentos anos, tão remota que mal podemos acreditar nela. Pois a Revolução desafia a crença. Parece incrivel que um povo inteiro fosse capaz de levantar e transformar as condições da vida cotidiana (Darnton, 1990, p. 35).

No entanto, isso aconteceu. E "ambígua, complexa, subversiva como continua sendo, mesmo duzentos anos depois, a Revolução ainda se provou refratária à domesticação" (Chartier, 2009, p. 15). Não é possível concebê-la em bloco, mas apenas sondá-la em seus múltiplos e contraditórios componentes.

Analisar a perspectiva de Lacroix sobre a instrução pública no período revolucionário é, inequivocamente, um modo de sondar a Revolução quanto a suas relações com a llustração, movimento inseparável de uma profunda vontade de disseminação dos conhecimentos e ampliação da instrução popular. 


\section{lluminismo, revolução e a questão da instrução pública}

$O$ debate científico, a necessidade de transformar a mentalidade conservadora e arcaica forjada pelas velhas instituições e, principalmente, dentre os letrados, pela formação jesuítica, então hegemônica, tinham se convertido em palavras de ordem: a queda da Bastilha havia tornado anacrônicas as discussões sobre a necessidade ou não da instrução do povo francês. Os debates passaram a ter como tema a forma como esse povo, produto da Revolução, deveria ser instruído. Para tanto, entraram em cena questionamentos sobre as políticas públicas voltadas à educação e os métodos pedagógicos que pautariam a nova instrução, de modo que se consolidasse o ideário revolucionário.

A expulsão dos jesuítas dos países católicos acarretou várias reformas educativas. $\mathrm{Na}$ França, de onde os jesuítas foram exilados em 1762, houve projetos de tais reformas em pauta durante todo o período da Revolução Francesa em suas várias fases: a Constituinte, a Assembléia Nacional, a Convenção Nacional e o Diretório.

Para Schubring (1985), uma das mais célebres obras relativas à educação nacional francesa, publicada em 1763, é o Ensaio sobre a educação nacional, de La Chalotais (1701-1785), que defendia a necessidade de serem elaborados manuais específicos para a formação de professores. Já para Piozzi (2007, p. 719), "a contribuição mais ousada e inédita para a estruturação de um ensino público democrático surge do projeto de Denis Diderot para a instrução gratuita, aberta a todos os filhos da nação, em todos os seus graus". Esse plano de instrução apresentado por Diderot, segundo a autora, exigia "que o percurso escolar fosse o mesmo para todos e [que fosse adotado] um método de ensino fundado no estímulo à inteligência e à criatividade, excluindo o treinamento de habilidades mecânicas e operativas e a transmissão de normas inquestionáveis de comportamento social" (p. 719). O projeto de instrução pública de Diderot, alicerçado na laicidade e no monopólio do ensino pelo Estado, porém, havia sido elaborado sob encomenda da imperatriz Catarina da Rússia em 1775.

Em abril de 1792, numa França ainda não republicana, mas que já respirava um clima de alterações institucionais, políticas e sociais, Condorcet apresenta à Assembléia Nacional um plano completo sobre a organização da instrução pública nacional, abrangendo todas as fases e instâncias de formação: o Relatório e projeto de decreto sobre a organização geral da instrução pública, inspirado em suas Cinco memórias sobre a instrução pública, cujos princípios orientadores eram o acesso universal, a gratuidade e a independência.

Segundo Souza (2008, p. 11-12), "para Condorcet, o processo de produção e difusão de conhecimentos, desde a escola elementar até as sociedades científicas, precisa ser independente de qualquer interferência externa de natureza religiosa, política ou ideológica". Dessa forma, a igreja, vista como criadouro de superstição e promotora de obscurantismos, estaria definitivamente afastada da instrução pública. Em suma, o Estado ocuparia o espaço que outrora fora dominado pela Igreja. O projeto de Condorcet "não chegou nem mesmo a ser votado pela Assembleia Legislativa, e foi sucedido por outras propostas durante a Convenção" (Gomes, 2008, p. 303), entretanto, serviu, efetivamente, como esboço para uma nova educação, radicalmente distinta daquela promovida ao longo do Antigo Regime, que se resumia a duas frentes de instrução: a educação primária como a escola do povo - e a educação secundária - que atendia apenas a aristocracia e a 
elite burguesa. É importante, e emblemático, lembrar que o Collège Mazarin ${ }^{5}$ foi construído para receber apenas 60 estudantes.

Condorcet propôs uma organização de escola em graus: o primeiro grau, com a duração de quatro anos, seria ministrado em escolas específicas presentes em todas as cidades $^{6}$. O segundo grau seria desenvolvido em instituições-polo, com vistas à centralizar o atendimento; e o ensino superior, em pequena quantidade, funcionaria em instituições implantadas nos centros mais populosos. Além de conceber efetivamente um projeto de instrução pública, Condorcet consolidava com clareza, nesse projeto, o ideário iluminista "indissociavelmente ligado à utopia do oferecimento a todos de uma instrução laica e gratuita ${ }^{7}$ de qualidade, mantida pelo poder público, a qual conduziria os cidadãos ao pensamento autônomo e crítico" (Gomes, 2005, p. 79) e trazendo à cena o pensamento científico e, em especial, a Matemática, que teria um lugar proeminente na nova educação. Para ele, "os conhecimentos elementares da aritmética são necessários não somente para satisfazer as necessidades imediatas da vida; mas também por sua relevância para assegurar a igualdade de todos os homens" (p. 72).

No que tange ao ensino nas universidades francesas, porém, é possível perceber que as medidas tomadas durante o período revolucionário atingiram, se muito, apenas o primário e o secundário. Segundo Dhombres (1980, p. 315-316), a indiferença desdenhosa pela universidade, em contraste com 0 fervor das assembléias revolucionárias nas propostas para os níveis mais elementares da instrução, pode ser explicada, em primeiro lugar, pela "fraqueza catastrófica da universidade francesa na segunda metade do século 18 e a confiança quanto à originalidade depositada somente nas academias".

No Antigo Regime, as universidades eram responsáveis pelos Colégios, então as escolas secundárias por excelência. Além deles, havia os Colégios das cidades, "confiados às congregações dos jesuítas, dos oratorianos, dos doutrinários e dos

\footnotetext{
${ }^{5}$ Sucessor de Richelieu, o cardeal Mazarin, querendo perpetuar seu nome como seu antecessor havia feito ao fundar a Sorbonne, mandou construir, com sua enorme fortuna, em meados do século 17 , o Colégio das Quatro-Nações, também conhecido como Colégio Mazarin. O nome da instituição faz referência às quatro regiões incorporadas à França como decorrência dos Tratados da Westfália e dos Pirineus, assinados, respectivamente, em 1648 e 1659. Sessenta estudantes dessas quatro nações (vinte de Flandres, Artois, Hainaut e Luxemburgo; quinze da Alsácia e outros territórios alemães; dez de Roussillon, Conflent e Cerdagne e 15 do Pignerol e dos Estados Papais), provenientes de famílias nobres, teriam bolsas garantidas para estudar, sob o regime de internato, na instituição que foi extinta sob Napoleão, sendo seu prédio, uma das mais notáveis construções à margem esquerda do Sena, defronte ao Louvre, ocupado em 1795 pelo Instituto da França, que reúne as Academias Nacionais Francesas (Babelon, 2001). Segundo Poirier (1996), pouco depois da fundação do Colégio, que ocorreu no início da década de 1660, o número desses estudantes bolsistas foi reduzido para 30 e outros alunos, não só os nobres das nações incorporadas, começaram a ser admitidos.

${ }^{6}$ A presença maciça de escolas primárias por todo o território francês faria delas, segundo a proposta, um espaço formativo não apenas para as crianças, mas para toda a população. De acordo com Boto (1996, p. 122), "as escolas primárias funcionariam também aos domingos, quando os professores deveriam ministrar as chamadas Conferências Públicas aos cidadãos jovens e adultos, interessados em atualizar e aprofundar o aprendizado que tiveram na primeira educação".

7 Outro projeto apresentado por Robespierre à Convenção Nacional e visto por historiadores como autoritário e fortemente nivelador foi o de Lepeletier, em cujo plano defendia-se "a criação de uma escola primária totalmente controlada pelo Estado, e obrigatória para todos, onde, em regime de internato, longe de seus ambientes de origem, crianças ricas e pobres conviveriam, em uma espécie de laboratório do "homem novo"' (Piozzi, 2007, p. 722). Mas embora tenha havido várias outras propostas, muitas delas objetivando a criação de uma escola gratuita, na França "o acesso universal à escola primária, laica, se institucionalizou apenas na Terceira República, após 1870” (Piozzi, 2007, p. 726).
} 
barnabitas" (Gomes, 2008, p. 34). A organização escolar dos colégios permitia que o professor pudesse trabalhar pedagogicamente, ao mesmo tempo, com todos os seus alunos. Eram divididos em classes compostas segundo o grau de instrução dos alunos. Segundo Savoie (2007, p. 13),

Essa forma de organização, que parece hoje em dia perfeitamente natural, teve sua origem histórica nos Países Baixos, no fim da Idade Média, nas escolas dos Irmãos da Vida Comum. Ela se impõe a toda a Europa com a difusão, no que se refere aos países católicos, do modelo dos colégios de ensino constituídos pela Universidade de Paris, no início do século XVI.

Nos colégios ensinava-se, inicialmente, apenas o Latim, com o tempo acrescentouse um pouco de estudo de Grego e de Francês ${ }^{8}$, e, conforme Durkheim, inexistiam disciplinas tematizando conteúdos científicos, como Matemática, Física, Química, Gramática Geral e as Ciências Naturais (Durkheim, 2002). Já de acordo com Schubring (1985), o ensino de Matemática ocorria, mas apenas no estágio final da formação e como parte da classe de Filosofia, antes da qual muitos alunos deixavam o colégio. Schubring acrescenta, ainda, que esse ensino de Matemática, mesmo sendo assegurado à última classe, só era oferecido se o estabelecimento dispusesse de profissionais qualificados para ministrá-lo.

A situação dos Colégios exemplifica claramente a estratificação social do século 18 e a singularidade da escolarização urbana frente à dos campesinos:

a grande maioria dos pequenos agricultores, fazendeiros, meeiros, empregados domésticos não sabe ler nem escrever, e não frequenta nem mesmo as escolas elementares. Assim, o colégio é um atributo sobretudo da média e da alta burguesia, para as quais o latim, principal objeto de estudo nessas instituições, ainda detém prestígio e representa um caminho de ascensão social. (Gomes, 2008, p. 35)

A diminuição drástica, durante o Antigo Regime, do número de alunos nos Colégios talvez possa ser creditada ao fato de ser mais comum as crianças trabalharem no campo, com suas famílias, ou visarem ao aprendizado de um ofício específico do que frequentarem as instituições escolares que, no caso dos Colégios, funcionavam em regime de internato, impactando a subsistência dos núcleos familiares. Além disso, acreditava-se à época, que o internato poderia causar o óbito das crianças. De acordo com Castan (2010, p. 415), "um fidalgo do baixo Languedoc não hesita em atribuir a morte sucessiva de seus três filhos ao fato de tê-los enviado cedo demais para um internato em La Flèche". Com a criação das Escolas Centrais pelo governo revolucionário, em substituição aos Colégios, implantou-se o externato no secundário, ainda que,

\footnotetext{
${ }^{8} \mathrm{Na}$ França às vésperas da Revolução, a língua francesa, propriamente, era, ainda, um conjunto disforme de dialetos não padronizados e desagregados. Imperava o patois, uma série de formas locais de comunicação e expressão. Pelo menos metade de toda a população francesa desconhecia a língua oficial. Da outra metade, apenas $12 \%$ tinham pleno domínio do código linguístico erudito (Boto, 1996).
} 
segundo Lacroix, no Essais, também houvesse internatos vinculados às Escolas Centrais ${ }^{9}$.

\section{As Escolas Centrais da França revolucionária}

No final do século 18, às portas da Revolução, a cidade de Paris possuía dez colégios, funcionando de forma integral, instalados à margem esquerda do Sena ${ }^{10}$. Como resultado das reformas educacionais, já nenhum colégio havia em Paris em 1791. Em 1793, a Comissão de Instrução Nacional do Departamento ${ }^{11}$ de Paris optou por substituir os extintos colégios por cinco institutos, as Escolas Centrais, o que se efetivou a partir das leis de 7 Ventoso ano 3 (25 de fevereiro de 1795), modificadas já em Brumário do ano 4 (outubro de 1795).

As Escolas Centrais abriram suas portas às vésperas do verão de 1796 . Depois de algumas discussões sobre onde instalá-las, foram inaugurados "os edifícios dos respectivos colégios: Quatre-Nations, Maison-professe dos Jesuítas (na rua SaintAntoine), e a abadia de Sainte-Geneviève, atrás do Pantheon" (Coeur, 2005, p. 55). Outras duas Escolas Centrais funcionariam em Paris, nos edifícios do Convento dos Capuchinhos, mas não saíram dos projetos. No panorama mais geral, as Escolas Centrais foram instituídas na proporção de uma por Departamento, geralmente uma em cada capital da comarca. No total, uma centena estava em funcionamento no ano de 1802, ano de sua extinção. Os critérios para a instalação dessas Escolas, segundo Coeur (2005, p. 54), impunham

designar os edifícios nos quais a disposição e o estado geral permitissem uma adequação rápida e pouco dispendiosa, entretanto, se deveria encontrar, junto a cada escola, uma biblioteca pública, um jardim, um laboratório de história natural, um laboratório de química e de física experimental, recursos dos quais dispunham poucos dos antigos colégios. Em Paris, como na maioria das cidades dos departamentos, as pesquisas indicam centenas de propriedades confiscadas do clero, dos imigrantes ou da realeza, desde o início da revolução.

Para Durkheim (2002, p. 280), nas Escolas Centrais, "tudo era novo; os quadros escolares, as matérias ensinadas, os métodos utilizados, os professores, tudo foi tirado do nada". Segundo Savoie (2007), as Escolas Centrais abandonaram o modelo de instrução adotado pelos colégios do Antigo Regime e optaram por um funcionamento mais aberto, oferecendo uma grande variedade e possibilidades de cursos. De acordo com Gomes (2008) e Schubring (1985), mesmo implantadas após a morte de Condorcet, as Escolas Centrais seguiam as disposições do seu Plano. Durkheim (2002) chega a associar

\footnotetext{
${ }^{9}$ Esse sistema de internato, então uma novidade, ao contrário daquele do Antigo Regime, não afastava de todo a criança do ambiente familiar.

${ }^{10}$ Projetos que visavam à instalação de colégios à direita do Sena, nos anos de 1760, fracassaram (Coeur, 2005).

11 "Com todo o debate, no começo da década de 1790 [...] a Assembleia trabalhava com uma energia legislativa sem paralelo na história da França, reorganizando a administração do país, bem como introduzindo os princípios de um sistema educacional moderno e revisando completamente o judiciário. A confusa estrutura de províncias do Ancien Régime foi substituída por 83 départaments de tamanho aproximadamente igual, dentro dos quais as comunas, dirigidas por conselhos municipais eleitos e com suas próprias pequenas unidades da Guarda Nacional, constituíam a unidade básica de governo" (Allan, 192, p. 144).
} 
diretamente essas instituições aos institutos do plano de Condorcet, designando-os como seu protótipo.

Apostando num sistema de módulos de ensino, o conteúdo de cada curso, relativo a uma única disciplina, era regido por um mesmo professor do início ao fim e dividido em seções que determinavam sua duração. Segundo Durkheim (2002, p. 276), "as seções dos diferentes cursos eram totalmente independentes umas das outras, não eram ligadas umas com as outras [...] e a velha unidade da aula encontrava-se dissociada numa pluralidade de cursos paralelos". Quem optava pelos cursos era o próprio aluno, ouvindo sua família. O estudante tinha, também, a oportunidade de escolher somente cursos que poderiam auxiliar na carreira escolhida. Para Lacroix (1838), esse formato oferecia aos jovens estudantes que possuíam pouco tempo para os estudos a oportunidade de se dedicar à profissão escolhida.

A filosofia de ensino seguia claramente uma tendência iluminista, privilegiando as ciências, o desenho e os conteúdos, em geral, modernos. No entanto, a realidade vivida no interior das Escolas Centrais nem sempre era a esperada, e em muitos casos afastava-se flagrantemente do que previam a legislação e as disposições filosóficas que Ihes serviam de fundamento.

Lacroix também tratará das alterações ocorridas no sistema de instrução francês a partir da lei do 3 Brumário ano 4, situando a divisão da instrução em três graus, seguindo com muita proximidade o sistema tripartite proposto no Plano de Condorcet: o primário, o secundário, correspondendo às Escolas Centrais, e as Escolas Especiais. As Escolas Primárias responsabilizar-se-iam pelo ensino da moral, da leitura, da escrita e do cálculo. As Escolas Centrais seguiriam um roteiro de estudos com duração de seis anos, divididos em três ciclos, ou seções, superpostos. O estudante ingressava no primeiro ciclo com doze anos de idade, no segundo com quatorze e no último com dezesseis anos.

No primeiro dos ciclos, havia um curso de História Natural e o segundo era dedicado totalmente à Matemática, à Física e à Química experimental. Lacroix defende que o curso de História Natural era efetivamente o mais apropriado para despertar nos alunos o gosto pelo estudo e, segundo ele, o curso de Matemática, ao compreender a aritmética, a álgebra, a geometria e a trigonometria, continha tudo o que era necessário saber para os estudos práticos relativos à mecânica, à arquitetura e à agrimensura. Ao longo dos ciclos, disciplinas visavam ao entendimento do homem: a História e a Legislação. Nessa estrutura, o estudo das letras foi reduzido a um curso de Latim, que visava apenas a dar uma noção da língua e não a ensiná-la, mesmo porque o tempo destinado a tal curso não possibilitaria um aprendizado efetivo, segundo o Essais, e um curso de Belas-Letras, totalmente teórico, nos primeiro e terceiro ciclos, respectivamente.

Essa drástica redução no estudo das Letras, para Durkheim (2002), indica claramente a intenção de permitir que o ensino literário apenas sobrevivesse. A organização interna das Escolas Centrais, prevista no título 2 da Lei de 3 Brumário, vem integralmente exposta no livro de Lacroix:

Há uma Escola central em cada departamento da República; nela o ensino é dividido em três seções.

Há na primeira seção:

Um professor de Desenho

Um professor de História natural 
Um professor de Línguas Antigas

Um professor de línguas vivas quando a administração departamental tiver obtido para essa disciplina a autorização do Corpo Legislativo

Há na segunda seção:

Um professor de elementos de Matemáticas

Um professor de Física e de Química Experimentais

Há na terceira seção:

Um professor de Gramática Geral

Um professor de Belas-Letras

Um professor de História

Um professor de Legislação. (Lacroix, 1838, p. 56-57)

Como o aluno ingressava no primeiro ciclo aos doze anos de idade, em média, supunha-se que este já recebera instrução anterior e não se ensinava, por exemplo, o francês admitindo, portanto, um conhecimento e um domínio prévios da língua. Durkheim (2002, p. 284) aponta que "abaixo das Escolas Centrais havia apenas as escolas primárias, cujo ensino era dos mais modestos. Entre elas e as Escolas Centrais havia uma lacuna que os homens da época sentiam muito bem, mas que não conseguiram preencher".

Sobre os professores das Escolas Centrais, Lacroix indica que sua contratação ocorria por concurso, cujas provas eram apreciadas por uma banca composta por três membros. Lacroix acredita que os professores professavam, como o verdadeiro objetivo do ensino, a preparação dos estudantes para se instruírem por si mesmos, e que inspiravam seus alunos a estabelecer uma relação de amor com o estudo e a vencer os obstáculos, insistindo nos métodos.

As Escolas Especiais foram propostas com vistas à extinção das instituições universitárias cuja existência parecia demais contaminada com a ideologia do Antigo Regime. No Essais, Lacroix apresenta parte do título 3 da Lei de 3 Brumário ano 4 em que estão indicadas as naturezas das onze Escolas Especiais previstas:

São indicados onze tipos de Escolas Especiais, a saber, as escolas:

De Astronomia

De Geometria e de Mecânica

De História natural

De Medicina

De Arte Veterinária

De Economia Rural

Das Antiguidades

Das Ciências políticas

De Pintura, de Escultura e de Arquitetura

De Música

De Escolas para surdos-mudos e para os cegos de nascença. (Lacroix, 1838, p. 58-59)

A vigência das Escolas Centrais foi breve, de 1795 a 1801, mas, segundo Lacroix, "durante o pouco tempo em que existiram [...] prestaram grandes serviços, adaptando ao ensino elementar os germes preciosos e fecundos acumulados nas lições da Escola 
Normal”12. De acordo com Gomes (2008, p. 306), faltaram às Escolas Centrais uma organização harmônica e uma concepção coerente das matérias que poderiam contribuir para a formação geral. Em 1802, dois novos tipos de estabelecimentos educacionais foram instituídos:

As Escolas Centrais eram obra da Convenção; sob o Consulado, isso bastava para desacreditá-las. [...] elas não respondiam em nada às concepções pedagógicas de Bonaparte. Sob pressão desse, foi votada a 11 de floreal do ano $X$ uma lei que as extinguiu e que acabou ao mesmo tempo com toda a pedagogia revolucionária. As Escolas Centrais foram substituídas por liceus, e pequenas escolas secundárias, preparatórias ao liceu, sob o nome de Colégios. A organização, as matérias e os métodos voltaram a ser o que eram sob o antigo regime. As ciências foram mantidas apenas por causa dos cursos militares. O Latim recuperou seu antigo predomínio. Era a volta ao antigo sistema. Tudo havia de ser refeito. (Durkheim, 2002, p. 285)

Em 1811, para cada três das antes chamadas Escolas Centrais foi instituído, aproximadamente, um Liceu, levando-se em consideração não o espaço territorial, mas a população a ser atendida. A criação dos liceus caracteriza o retorno de uma organização escolar semelhante à dos colégios do Antigo Regime.

Durante a Restauração, os Liceus napoleônicos transformaram-se nos colégios reais, nos quais, de acordo com Durkheim, havia certa repressão ao ensino científico. Gomes (2008) aponta, quanto ao ensino científico, que "as ciências e a matemática ainda detinham certa importância, já que a aritmética, a álgebra, a geometria, a trigonometria, a agrimensura, um pouco de óptica e astronomia eram neles ensinados" (p. 311), e concorda com Schubring ao afirmar que o ensino nos Liceus pautava-se no modelo jesuítico, oposto, portanto, àquele pretendido durante a Revolução, fundamentado nos ideais iluministas. E assim, aos poucos, o ensino das Ciências foi cedendo lugar ao retorno maciço do império das Letras. A matemática passou todo o século 19 sem ser reconhecida como importante para a formação do indivíduo e, de acordo com Schubring (1985), somente no início do século 20 se estabelecerá um equilíbrio entre o ensino de letras e o de ciências.

${ }^{12}$ Criada na França revolucionária, a Escola Normal serviu de modelo às demais escolas de formação de professores que se espalharam pela Europa, chegando ao Brasil em 1835. Segundo Piozzi (2007), as Escolas Normais eram as únicas efetivamente abertas aos menos favorecidos. A formação nelas facultada restringia-se aos conteúdos considerados elementares, à época, e aos ensinamentos morais e religiosos que posteriormente seriam levados às crianças pobres de uma Escola Primária também pobre. De acordo com Dhombres (1980), as duas instituições mais notáveis do período revolucionário nasceram apenas após o Termidor: a École Polytéchnique e a École Normale, criadas pela Convenção Nacional a partir dos decreto de fundação aprovados no 7 Vendemiário e no 9 Brumário ano 3, respectivamente. Schubring (1985) afirma que a instituição das Escolas Primárias em toda a República demandou uma formação de professores rápida visando a atingir, em pouco tempo, um grande número de indivíduos. Para esse autor, essa foi a única razão para a fundação da Escola Normal. Segundo Dhombres (1980), as Escolas Normal e Politécnica eram, desde suas origens, bem diferentes: a Politécnica foi prevista para durar e a Normal era uma estratégia emergencial, para divulgar normas quanto aos métodos de ensino formando mestres que pudessem, logo que possível, implementar em cursos o que haviam aprendido. Paralelamente, acordos políticos permitiram que antigos representantes do clero se tornassem instrutores tanto em instâncias públicas quanto privadas. A Convenção Nacional, em decorrência dessa situação, suprimiu a Escola Normal apenas quatro meses depois de iniciado seu funcionamento (Schubring, 1985). Ela reaparecerá por volta de 1808-1810, na era Napoleônica. 
É provável que esse estado de coisas, em que impera a alteração frequente entre modelos educacionais, bem provavelmente tenha motivado Lacroix a elaborar o Essais, um libelo ao mesmo tempo memorialístico e em favor do modelo revolucionário das Escolas Centrais e da importância do ensino das Ciências e, em especial, da Matemática, num momento em que a tendência de retorno ao conservadorismo se insinua. Vamos, a seguir, concentrar-nos especialmente na visão de Lacroix quanto a esses temas na obra que focalizamos neste artigo.

\section{Sobre as considerações e reflexões presentes nos Ensaios sobre o ensino em geral e o de Matemática em particular}

O esclarecimento dos novos tempos, segundo Lacroix, influenciou a Assembleia Constituinte e o avanço dos debates foi tamanho que a Convenção Nacional pensou em reorganizar o ensino. Membros do Comitê de Salvação Pública propuseram a formação da Escola Central de Trabalhos Públicos que, fundada em 1794 e já em 1795

transformada na École Polytéchnique, deu grande impulso à cultura da Matemática. A Escola Central de Trabalhos Públicos, tendo obtido sucesso, serviu de parâmetro para a criação de uma instituição com o objetivo precípuo de formar os professores que os novos tempos reclamavam, a Escola Normal.

O encadeamento do discurso de Lacroix fundamenta-se, portanto, no núcleo do pensamento lluminista, o enaltecimento dos progressos científicos, sua divulgação e a exaltação da razão, para perceber a cultura em geral, e particularmente a educação francesa, como ecos das Luzes. Situa-se nessa esteira não apenas a importância dos iluministas, mas também a da Matemática, pois "é impossível não reconhecer a influência que a Matemática teve sobre a restauração das ciências e como, atraindo os olhares, ela se tornou o objeto principal da primeira educação" (Lacroix, 1838, p. 31).

Reavivando $\mathrm{o}$ ataque dos philosophes às instituições do Antigo Regime e à educação jesuítica, o autor vincula as Luzes, a Matemática e o diálogo entre as ciências ao projeto inovador das Escolas Centrais. O vetor inicial para a instrução das crianças deveria ser colocado sobre as Ciências, em detrimento das Letras, opção julgada nociva por alguns autores. Entretanto, essa questão, segundo Lacroix, que aqui faz um exercício estratégico de imparcialidade, não estava completamente resolvida:

Podemos, enfim, questionar se a prioridade das Ciências sobre as Letras que perdurou por alguns anos na educação - foi tão nociva a essas últimas quanto alguns escritores insistem em repetir sem provas. É ainda uma questão em aberto, em função da diversidade de opiniões, saber por qual de nossos conhecimentos é preciso começar a instrução das crianças: se o estudo das línguas é o único que convém na primeira infância; se é possível substituí-lo com vantagem pelo da História Natural ou ainda pelo da Geometria Prática e das operações de cálculo convertidas em algo mais compreensível pela combinação de medidas de extensão, assim como o fez Pestalozzi. Quem pode garantir que aqueles cujo gosto particular tenha acelerado os progressos não voltarão às Letras quando sentirem necessidade e não preencherão facilmente o vazio de sua primeira educação; ao passo que eles seriam tão alheios às Letras 
quanto às Ciências se não tivessem encontrado, no início, o que a natureza os chamava especialmente a cultivar? (Lacroix, 1838, p. 33-34)

Na introdução de sua obra, Lacroix explicita sua determinação em defender os ideais das Luzes, tomando como referências os grandes nomes da ciência de seu tempo. Seu discurso empolgado não só defende as ciências como portadoras de uma verdade que a injustiça, a religião e o atraso, tomados como sinônimos, dos antigos sistemas que gerenciavam a educação do Antigo Regime impediam de vir à tona com a sua extraordinária força, como também estabelece, na sequência quase linear de seus argumentos, a influência das Luzes como parâmetro para a criação de instituições escolares que constituiriam um sistema nacional de educação diferenciado, adequado e justo.

Ainda que pareça ceder espaço aos discursos contrários, quando se permite considerar a posição de alguns detratores, Lacroix é claro em sua posição: as novas concepções permitem vislumbrar um estado de coisas que deve ser arduamente defendido e a Matemática, nesse sistema, deve ocupar um estágio diferenciado, superior, privilegiado. Essa Matemática, que no interior das instituições escolares pode promover a articulação entre as ciências é, por sua própria natureza, consistente com o que se deseja para a formação do cidadão.

Embora o autor declare fervorosamente os fundamentos que defende e realce a capacidade notável de expressão de alguns escritores que o influenciam, ele não disputa com esses escritores no que diz respeito ao modo de redação do texto. Lacroix não parece pretender esgrimir com Voltaire: seu discurso não tem a pretensão de inscrever-se como arte, mas como argumentação científica, clara e centrada na competência quanto ao tema que defende: a nova Educação e a posição da Matemática nesse cenário que é novo.

É um discurso competente, correto, logicamente encadeado, de frases sonoras e períodos longos, mas sem pretensões artísticas. Em seu texto são citados cerca de meia centena de nomes aos quais o autor vincula comentários que, embora às vezes sucintos, são suficientes para exibir seu domínio sobre as conquistas científicas da época, seus temas, seus autores, suas áreas, suas personalidades. É essa, pois, sua estratégia discursiva. Suas considerações, nesse texto introdutório, apoiam-se menos na experiência prática como professor e administrador e mais no conhecimento profundo também uma experiência, mas especializada, técnica, intelectual - do mundo em que transita, um mundo que seguramente tem condições de suportar a pesada carga de conduzir uma educação diferenciada, para melhor, em comparação ao que o Antigo Regime e seus antigos colégios ofereciam. O tom professoral, tão especializado quanto experiente, tão comprometido quanto sábio, alia-se então ao pacto que Lacroix já havia estabelecido contratualmente com seu leitor, tomado pelo autor como aprendiz na exposição do objetivo da obra.

Instrução pública e desenvolvimento da ciência são temas interligados que, junto à continuidade da crítica ao antigo modelo de ensino, que se "debruçava sobre questões inúteis de Teologia e Metafísica" frequentam a primeira parte do Essais, composta por uma história abreviada do ensino na França do começo do século 19, segundo Lacroix. 
Comentamos, a partir de agora, a exposição do autor nesse texto, intitulado Do ensino, em geral, durante o século 18.

Lacroix afirma que os escritos de Aristóteles, considerados obscuros, retardaram o nascimento da verdadeira filosofia. Para Lacroix, o mais importante nesses trabalhos "foi sua dialética, sem dúvida extremamente bem concebida, mas quase sempre supérflua e frequentemente nociva à busca da verdade" (Lacroix, 1838, p. 41). Só com Montaigne e Bacon instala-se a filosofia verdadeira, e as descobertas dessa verdadeira filosofia se "sucedem tão rapidamente que seria impossível citá-las todas aqui sem ultrapassar os limites que impus para esta obra" (Lacroix, 1838, p. 47). De tais descobertas, que subsidiam as Ciências, se deveria nutrir a instrução: "Conforme o quadro de riquezas que as ciências acabam de conquistar em tão pouco tempo, quem não esperaria ver uma mudança no ensino público?" (Lacroix, 1838, p. 48).

No entanto, escreve o autor, uma mobilização em torno dessas conquistas da ciência não afetou imediatamente a universidade francesa, o que implicou lentidão quanto à efetivação de uma nova configuração para o ensino público francês.

É por volta da metade do século 18 que tem início um movimento contra a égide da Igreja, quando o Estado faz uma tentativa de agregar ao estudo das línguas antigas, então dominante, o da língua materna, da Matemática, da Física e da História Natural: restringiu-se o escopo da Metafísica, havendo, então, espaço para as ciências. Para Lacroix, a criação das Escolas Militares foi uma das grandes experiências para o aperfeiçoamento do ensino público. O desejo, compartilhado por muitos, de acordo com o autor, de alterar a instrução pública na França manifestou-se desde o início da Revolução e implicou a elaboração da Lei do 3 Brumário ano 4 que, em particular, estabelecia os princípios para a criação das Escolas Centrais.

Pela Lei, o ensino passou a ser dividido em três graus: Escolas primárias, Escolas Centrais e Escolas Especiais. Nas Escolas Primárias, ensinar-se-ia a leitura, a escrita, o cálculo e os elementos da moral. Os professores, que recebiam um auxílio residência do governo e cujos salários eram pagos pelos pais dos alunos, teriam a liberdade de escolher o que e como ensinar. A instrução pública, portanto, não era gratuita, mas a administração do Departamento podia isentar os alunos carentes de pagar tal contribuição, ainda que apenas um quarto dos alunos dessas escolas pudessem beneficiar-se dessa dispensa.

Segundo as disposições do capítulo 2 da lei, haveria uma Escola Central em cada Departamento e nelas seria obrigatória a instalação de uma biblioteca pública, um jardim, uma sala de História Natural e uma de Física e Química experimentais. Seus professores eram escolhidos por uma Comissão de Instrução composta por três membros. Nelas, a instrução também não era gratuita e de cada estudante eram cobrados 25 francos. Como também ocorria nas escolas primárias, um quarto dos alunos poderia ser isentado das taxas, desde que considerados oriundos de famílias de baixa renda.

As Escolas Especiais, segundo Lacroix, foram organizadas a partir do modelo das Escolas Centrais Normais, com a diferença de serem instituições de ensino temáticas. No entanto, as várias dificuldades pelas quais passou a educação primária não permitiram que essas escolas pudessem ter qualquer utilidade. O plano de instrução estabelecido pela Lei do 3 Brumário só foi realmente efetuado quanto às Escolas Centrais e, mesmo assim, conforme o Essais, de modo incompleto. 
A partir dessa exposição, Lacroix inicia uma análise do plano das Escolas Centrais e considera tanto os cursos que, segundo a lei, seriam desenvolvidos nessas escolas, quanto o modo como os professores das Escolas Centrais concebiam, ou deveriam conceber segundo seus princípios, as práticas que professavam. A instrução seria organizada a partir do curso de História Natural, "mais adequada que qualquer outra ciência para promover o gosto pelo estudo" (Lacroix, 1838, p. 64), que motivaria, então, as consequentes discussões sobre as Ciências Físicas que, para serem proveitosas, exigem o domínio da "Física, propriamente dita, da Química, da Geometria".

Ao professor, que não pode nem deve pensar em formar naturalistas, mas precisa procurar revelar ao jovem a vocação que este recebeu da natureza", caberia escolher os assuntos da História Natural, priorizando o estudo dos elementos que demandassem o mínimo conhecimento acessório. A classificação e o reconhecimento são capacidades a serem continuamente desenvolvidas, seja na História Natural, seja quanto aos resultados posteriores de Física e Matemática que os professores apresentarão. Uma síntese da composição e do modo de tratamento dos conteúdos recomendados para serem desenvolvidos nas Escolas Centrais passa ser, então, o foco de Lacroix, que discorre sucessivamente sobre as disciplinas: Matemática, Belas Letras, Latim, História, Geografia, Legislação, Moral.

Lacroix também sublinha que o oferecimento dos cursos era contínuo e a sequência em que seriam realizados era uma opção do aluno, que para isso deveria consultar sua família. No entanto, por ser oferecida a possibilidade de uma educação parcial, com cursos de duração limitada que, de certa forma, podavam o avanço no ensino das ciências, Lacroix declara que: "ouço, nesse sentido, muitas queixas de que as Escolas Centrais não podiam formar mais que semicientistas” (Lacroix, 1838, p. 83). Contudo, para ele, essas instituições "atendiam [...] às condições que os philosophes do século 18 desejavam para os antigos estabelecimentos, já que elas apresentavam uma instrução completa em que todas as partes eram úteis e podiam ser reunidas ou separadas conforme o interesse" (Lacroix, 1838, p. 84).

Lacroix não se detém apenas nas disposições gerais e técnicas. Aos poucos, detalha o cotidiano dessas escolas, a disciplina, as avaliações, as práticas diárias e as estratégias didáticas, enquanto defende suas concepções sobre o sucesso dos melhores métodos de ensino e a ineficácia dos castigos para o despertar da inteligência. Nas referências à forma como alguns professores procediam, podemos perceber a coexistência, numa mesma instituição, de práticas e posturas diferenciadas entre os docentes, o que reforça a liberdade dada a eles quanto à escolha de seus métodos e dos conteúdos a serem tratados. Segundo Lacroix, a função do professor não é a de ser como um pai para seus alunos, é "muito mais dirigir o ensino do que se entregar ao simples mecanismo pelo qual se faz guardar na memória dos alunos aquilo que ele esclareceu a eles" (Lacroix, 1838, p. 114).

É interessante observar que Lacroix mescla a essas considerações gerais sobre o trabalho dos professores e suas relações com os estudantes, comentários relativos à sua própria experiência docente e de autor de livros didáticos. A passagem abaixo, na qual o autor se refere ao uso dos materiais escritos especialmente para subsidiar o ensino, exemplifica esse modo de construção textual: 
O professor poderá frequentemente aproveitar das observações dos alunos e dos meios que tiverem empregado para levantar, por eles mesmos, as dificuldades que os detiveram em seu estudo particular. Estimuladas pelos incentivos do professor, pela aprovação dos colegas, suas jovens inteligências se elevarão, às vezes, a novos pontos de vista, e eles serão capazes de sugerir, para a obra que tiverem nas mãos, simplificações e correções que talvez não fossem apresentadas ao autor. Confesso, lembrando-me com prazer do zelo e da candura com que os alunos faziam essas sugestões, a gratidão que devo a um grande número de jovens tão estudiosos quanto amáveis, que tive a felicidade de ter em minhas aulas: minhas obras, empreendidas unicamente com o objetivo de poupar-lhes o esforço de recorrer a materiais esparsos, ganharam muito com suas observações, quaser sempre justas e frequentemente muito elegantes. (Lacroix, 1838, p. 101-102)

Mesmo com os cuidados tomados para a implementação dos programas, as indicações favoráveis quanto à formação continuada dos professores, a liberdade prevista para que esses professores pudessem adequar suas atividades, entre vários aspectos, as Escolas Centrais, como já foi dito, tiveram vida curta. Apesar de ceifadas muito cedo, devido às instabilidades políticas do momento, as Escolas Centrais deixaram, segundo Lacroix, suas lições positivas:

elas se aliaram logo à École Polytéchnique, fornecendo-lhe um grande número de sujeitos instruídos, dentre os quais vários se destacaram eminentemente. Elas também transmitiram e repetiram o poderoso impulso que essa bela escola deu à cultura da Matemática em toda a França; mas foi sobretudo pela influência que exerceram sobre a instrução geral que as Escolas Centrais deixaram sua marca, o que seria lembrado pelos amigos do progresso da razão durante muito tempo depois da sua extinção. É por elas que as sementes lançadas na Escola Normal foram desenvolvidas e seus frutos espalhados por toda a nação. Os professores dessas escolas se apressaram em preparar para seus alunos as lições dadas por seus próprios mestres na grande escola, e várias ciências penetraram finalmente em lugares onde não eram conhecidas nem mesmo pelo nome. (Lacroix, 1838, p. 126-127)

Ao final da primeira parte do Essais, Lacroix apresenta os programas de cursos oferecidos pelas Universidades de lena e Göttingen para os anos 1802-1803. Essa apresentação tem sentido à luz da afirmação de que "a associação dos primeiros elementos das ciências físicas e matemáticas, das ciências morais e políticas aos das Belas-Letras [aplicada nas Escolas Centrais] [...] era apenas uma cópia reduzida e sumária do sistema de curso adotado nas primeiras universidades do norte" (Lacroix, 1838, p. 84), complementada em nota de rodapé à mesma página ("Como me pareceu que o ensino nessas escolas, embora anunciado regularmente nos jornais alemães, não era ainda muito conhecido na França, julguei importante inserir dois programas no fim da primeira parte para mostrar o espírito desses estabelecimentos, que eram bem diferentes daqueles que tínhamos em outros tempos com o mesmo nome").

Em sequência, como que num tópico complementar à primeira parte, Lacroix retoma as faculdades do entendimento humano de acordo com Bacon e os enciclopedistas, dedicando-se a discorrer sobre a memória, a razão e a imaginação, temas que operam como classificadores gerais num sistema de organização do conhecimento disponível nos 
livros, daí a importância do curso de Bibliografia, a ser tratado nas Escolas Centrais. A bibliografia, o tratamento cuidadoso dessa bibliografia e mesmo a disposição física dos livros no espaço da biblioteca apóiam o tratamento diferenciado e abrangente das ciências.

A elaboração textual de Lacroix para a primeira parte de seu livro não difere da usada na introdução: é sóbria, com longos parágrafos, de estilo elegante, sem ser propriamente literária. Lacroix mantém-se professoral: não apenas descreve, segundo sua experiência, o contexto educacional francês, mas ensina, dá indicativos de como determinadas ações deveriam ser implementadas ou abandonadas. Um exemplo cabal disso é a questão que ele deixa a modo de exercício, usando o "Quadro de casamentos" para os professores de Matemática e Legislação, no último parágrafo dessa primeira parte. De fato, Lacroix propõe que seja trabalhado, na escola de cada Departamento, um quadro anualmente elaborado dos casamentos da população de cada cidade com a finalidade de "fornecer os dados para todas as questões de probabilidade às quais os casamentos podem conduzir" (Lacroix, 1838, p. 164).

Ele completa sua explicação em nota de rodapé dizendo que, como "o divórcio era então permitido, desejava-se determinar suas consequências, mas não apenas por meio de declarações vagas, pois todas as ações humanas têm efeitos passíveis de ser traduzidos em números, e, consequentemente, de ser avaliados com precisão" (Lacroix, 1838, p. 164). Ao final do Plano do Anuário de um Departamento, apresentado quando termina a primeira parte, encontra-se um esboço de quadro de casamentos proposto pelo autor para que os professores pudessem preencher e utilizar.

Observa-se, ainda, que nessa parte inicial do livro que ocupa, na edição francesa de 1838, 126 das 360 páginas, continuam presentes de forma muito nítida os iluministas como fundamentação principal para os comentários do autor.

\section{Algumas palavras para concluir}

A obra que Lacroix designou como um ensaio sobre o ensino, em geral, durante o século 18 na França é, mais propriamente, ainda que o autor nos dê sinais de um cenário mais amplo quanto às instituições e legislações, um detalhamento das práticas de ensino das Escolas Centrais e dos fundamentos dessas práticas. É nítida a defesa apaixonada do autor em relação a esse grau da instrução pública implantado pela Lei do 3 Brumário ano 4, ainda que em alguns momentos se possa compreender que a inovação proposta com a criação dessas Escolas, que causou resistências, como parece ser usual face tanto à liberdade dada aos professores e mesmo aos alunos, que escolhiam a sequenciação e os conteúdos a serem cursados, quanto à presença de temas e abordagens muito distintas das que eram ensinadas nos antigos Colégios, tinha ainda pontos a serem refinados para que o desenvolvimento da instrução fosse plenamente adequado.

As instabilidades políticas do período revolucionário, a manutenção de práticas antigas, como as de favorecimento, exemplificadas por Lacroix quando cita a substituição de professores implicada com a troca das autoridades locais, a falta de agilidade dos órgãos públicos, por exemplo, em atender as necessidades de contratação ou material para o bom funcionamento da instituição, as críticas dos que, habituados aos Colégios do Antigo Regime prezavam mais pelas formas consagradas de instrução, desconfiando das alterações propostas, fizeram com que esse sistema educacional tivesse existência curta 
a ponto de não ser possível uma avaliação mais aprofundada dos resultados que obteve ou obteria caso tivesse sido mantido.

A intenção para as Escolas Secundárias, em seus três graus, era privilegiar o debate científico e a vinculação entre os campos do conhecimento humano. A lógica do discurso de Lacroix é um exemplo emblemático dessa proposta, perfeitamente compreendido, por exemplo, pelo modo como se propõe, em seu texto, a utilização e até mesmo o armazenamento dos livros: o critério para catalogação bibliográfica segue a divisão proposta por Bacon e pelos enciclopedistas para tratar das faculdades humanas, defendido num encadeamento lógico de justificativas que coloca cada obra, cada autor, cada tema e cada área num espaço específico.

O detalhamento de Lacroix, quanto ao conteúdo dos cursos e os termos da legislação, oferecem chaves significativas para percebermos a estrutura das Escolas Centrais. O apoio que o autor busca, em duas universidades alemãs, para fundamentar a novidade dessas intenções revolucionárias tanto mostra a familiaridade com sistemas educacionais externos à França, mantendo o clima de autoridade e legitimando as boas relações que o autor estabelece a sua volta, quanto, de modo implícito, parece defender, esta é uma interpretação nossa, que o desenvolvimento mais apurado dessas universidades externas, lena e Göttingen, está vinculado à diluição das religiões pelo território alemão, ainda que o catolicismo seja até hoje uma das principais religiões da Alemanha, o luteranismo tem presença marcante, desde a Reforma Protestante, principalmente no Norte do país, onde estão as universidades que Lacroix toma como exemplo.

O texto de Lacroix, cujo teor autobiográfico se configura a partir da regência de um pacto autobiográfico com o leitor (Lejeune, 2008), como já sublinhamos, apoia-se recorrentemente no ideário iluminista e, explicitamente, nas concepções dos philosophes. Nessa seção primeira, que pretende tematizar o ensino em geral, reitera-se a crítica às antigas instituições, que servem como contraposição às novas propostas. Caracteriza-se, particularmente na parte da obra tematizada por este artigo, um discurso claramente dicotômico, no qual os pólos são ocupados pelo obscurantismo de um lado e pelas Luzes do outro; o Antigo Regime de um lado, o período revolucionário do outro; a Filosofia antiga e a Teologia de um lado, o lluminismo e as Ciências do outro.

\section{Referências}

ALLAN, Tony. (ed.). Ventos revolucionários (1700-1800). São Paulo: Time-Life/Abril, 1992.

BABELON, Jean Pierre. Louis Le Vau at the Collège Mazarin: Rome in Paris? Paris: Secretariat de l'Académie des Beaux-Arts, 2001.

BENJAMIN, Walter. Paris: capital do século 19. Sociologia. São Paulo: Ática, 1991.

BOTO, Carlota. A escola do homem novo: entre o iluminismo e a revolução francesa. São Paulo: Unesp, 1996.

CASTAN, Nicole. O público e o particular. In: ARIĖS, Philippe; CHARTIER, Roger (org.). História da vida privada, 3: da Resnascença ao Século das Luzes. São Paulo: Companhia das Letras, 2010, p. 407-453. 
CHARTIER, Roger. Origens culturais da revolução francesa. São Paulo: Unesp, 2009.

COEUR, Marc Le. Os liceus na cidade: o exemplo parisiense (1802-1914). In: BENCOSTTA, Marcus Levy Albino (orgs). História da educação, arquitetura e espaço escolar. São Paulo: Cortez, 2005, p. 281-324.

DARNTON, Robert. O beijo de Lamourette: mídia, cultura e revolução. São Paulo: Companhia das Letras, 1990.

DHOMBRES, Jean. L'enseignement des Mathématiques par la "méthode révolucionnaire". Les Leçons de Laplace à l'Ecole normale de l'an III. Revue D'Histoire des Sciences. Tome XXXIII, n. 4, octobre, 1980, p. 315-348.

DOMINGUES, João Manuel Caramalho de Melo. The calculus according to S. F. Lacroix (1765-1843). PhD Thesis. Middlesex University, 2007.

DURKHEIM, Émile. A evolução pedagógica. Porto Alegre: Artes Médicas, 2002.

GOMES, Maria Laura Magalhães. Valores da cultura matemática nas vozes de pensadores franceses do século das Luzes. Zetetiké, Campinas: Unicamp, v. 13, n. 24, jul./dez., 2005, p. 47- 80.

GOMES, Maria Laura Magalhães. Quatro visões iluministas sobre a educação matemática: Diderot, D’Alembert, Condillac e Condorcet. Campinas: Unicamp, 2008.

LACROIX, Silvestre François. Essais sur l'enseignement en general et sur celui des Mathématiques en particulier. Paris: Bachelier, 1838.

LEJEUNE, Philippe. O pacto autobiográfico: de Rousseau à Internet. Belo Horizonte: UFMG, 2008.

ORTIZ, Renato. Walter Benjamin e Paris: individualidade e trabalho intelectual. Tempo Social, São Paulo: USP, v. 12, n. 1, 2000, p. 11-28.

PIOZZI, Patrícia. Utopias revolucionárias e educação pública: rumos para uma nova "cidade ética". Educação e Sociedade. Campinas: Unicamp, v. 28, n. 100, 2007, p. 715735.

POIRIER, Jean Pierre. Lavoisier: chemist, biologist, economist. Philadelphia: University of Pennsylvania Press, 1996.

QUEIRÓS, José Maria Eça de. A cidade e as serras. Cotia: Ateliê, 2011.

SAVOIE, Philippe. Criação e reinvenção dos liceus: 1802-1902. História da Educação. Pelotas: Asphe, v. 11, n. 22, 2007, p. 9-30.

SCHUBRING, Gert. Análise histórica de livros de matemática. Campinas: Autores Associados, 2003.

SCHUBRING, Gert. Essais sur l'histoire de l'enseignement des mathématiques, particulièrement en France et en Prusse. Recherches en Didactique des Mathématiques, v. 5, n. 3, 1985, p. 343-385.

SOUZA, Maria das Graças. Apresentação. In: CONDORCET. Cinco memórias sobre a instrução pública. São Paulo: Unesp, 2008, p. 7-13. 
ANTONIO VICENTE MARAFIOTI GARNICA é doutor em Educação Matemática pela Unesp de Rio Claro, livre-docente pelo Departamento de Matemática da Faculdade de Ciências da Unesp de Bauru. Docente na Unesp/Bauru e nos programas de Pós-Graduação em Educação para a Ciência (Unesp/Bauru) e em Educação Matemática (Unesp/Rio Claro).

Endereço: Avenida Luiz E. C. Coube, s/n - 17030-360 - Bauru - SP - Brasil.

E-mail: vgarnica@fc.unesp.br.

MARIA LAURA MAGALHÃES GOMES é doutora em Educação pela Unicamp. Professora do Departamento de Matemática da Universidade Federal de Minas Gerais e do Programa de Pós-Graduação em Educação da mesma universidade. Endereço: Av. Antônio Carlos, 6627 - 31270-901 - Belo Horizonte - MG - Brasil. E-mail: mlauramgomes@gmail.com.

MIRIAN MARIA ANDRADE é doutora em Educação Matemática pela Unesp de Rio Claro. Professora do curso de Matemática da Faculdade de Ciências Integradas do Pontal, da Universidade Federal de Uberlândia.

Endereço: Av. prof. José Vieira de Mendonça, 1535 - 38307-034 - Ituiutaba - MG Brasil.

E-mail: andrade.mirian@gmail.com.

Recebido em 23 de fevereiro de 2012.

Aceito em 9 de agosto de 2012. 